\title{
O ESTRANGEIRO, O MODERNO E A AÇÃO HUMANA: AS LITERATURAS ESTRANGEIRAS MODERNAS EM TEMPOS DE PÓS E MUITO MAIS...
}

\author{
Sandra Regina Goulart Almeida \\ Universidade Federal de Minas Gerais
}

\begin{abstract}
Resumo: O artigo discute a questão das literaturas estrangeiras modernas na contemporaneidade, principalmente como uma área de estudo que engloba várias tendências teóricas e diversos enfoques. Partindo das teorizações de Spivak sobre o projeto coletivo que deve informar os estudos de área, o artigo busca avaliar como as literaturas estrangeiras modernas procuram refletir sobre seu objeto de estudo específico, que envolve termos complexos como o estrangeiro, o moderno e a ação humana.
\end{abstract}

Palavras-chaves: estrangeiro, moderno, ação humana, literatura estrangeira moderna,

\begin{abstract}
The article discusses the issue of modern foreign literatures in our contemporary world, mainly as an area of study that encompasses various theoretical tendencies and diverse approaches. Starting from Spivak's theories about the collective project that informs area studies, the article attempts to evaluate how modern foreign literatures ponder about its specific object of study, which involves complex terms such as the foreigner, the modern and human action.
\end{abstract}

Keywords: foreigner, modern, action human, modern foreign literature.

se como professores de literatura nós pudermos ensinar a ler, a literatura pode ser nossa mestra bem como nosso objeto de pesquisa [. . . ] Senão, quem ficará no lugar do "humano" do "humanismo" ao fim do dia, mesmo em nome da diversidade? Nós precisamos considerar as "Coletividades" (Spivak, 2003, p.23).

\section{Momento 1: Preâmbulo}

Falar em pesquisa na área de literaturas estrangeiras modernas em tempos de pós- é, para nós todos, um grande desafio, pois nesse âmbito estamos incluindo um enorme leque de conceitos teóricos e críticos abrangentes e muitas vezes conflitantes. Apenas à guisa de exemplo podemos citar - além dos conceitos mais comuns do pósestruturalismo, pós-modernismo e pós-colonialismo - o pós-feminismo de Ann Brooks e outras teóricas feministas (não no sentido corrente de "anti-feminismo", mas na concepção de um feminismo contemporâneo com respeito às diferenças e com ênfase no pluralismo), o pós-orientalismo de Edward Said, o pós-ocidentalismo de Walter Mignolo, o pós-nacionalismo de Arjun Appadurai, e, mais recentemente, a pósmemória teorizada por Beatriz Sarlo, entre vários outros.

O paradoxo inevitavelmente evocado pelo prefixo "pós" - que pode se referir tanto a uma ruptura quanto a uma continuidade com o que prevalecia num momento anterior não se dilui facilmente com uma simples definição de termos, mesmo porque esses são 
conceitos que, em muitos casos, deveriam ser usados em sua forma plural, apontando para o contexto multifacetado para o qual acenam.

Beatriz Sarlo, em seu recente, Tempo passado: cultura da memória e guinada subjetiva (2007), ao discutir o termo pós-memória, afirma: "O gesto teórico parece então mais amplo que necessário. Não tenho nada contra os neologismos criados por aposição do prefixo pós, pergunto apenas se correspondem a uma necessidade conceitual ou se seguem um impulso de inflação teórica" (2007, p. 95). O conceito de inflação teórica, sugerido por Sarlo com relação ao que ela vê como o abuso do "pós", é compartilhado por alguns teóricos da contemporaneidade que, ao falarem dos tempos modernos ou o que costumamos chamar de "tempos de pós", preferem optar por um conceito de moderno - que nos é muito útil neste caso, pois estamos argumentando acerca de "literaturas modernas" hoje - em seu sentido mais amplo, livre, alternativo e inclusivo.

Andreas Huyssen, por exemplo, argumenta que termos como a "modernidade às soltas/livre" (modernity at large) de Arjun Appadurai e as modernidades alternativas de outros críticos parecem ser termos mais apropriados para se entender o presente momento de perspectivas globais do que a noção, por exemplo, de pós-modernismo, pois um termo mais geral "evita a armadilha de acusações de homogeneização tanto quanto rejeita a ilusão de uma pluralidade feliz de modernidades" (2002, p. 20). Da mesma forma, Garcia Canclini afirma o quanto é intricado ser moderno hoje em dia, já que "é possível pensar que ser moderno perdeu o sentido neste tempo em que as filosofias pós-modernas desacreditam os movimentos culturais que prometem utopias e auspiciam o progresso" (2000, p. 17). Cabe ressaltar também, seguindo a teorização de García Canclini, que ao falar de moderno (em um sentido mais amplo, como o faz Appadurai, Huyssen, Bauman e mesmo Spivak), estamos muitas vezes falando de uma complexa "heterogeneidade multitemporal de cada nação" (García Canclini, 2000, p. 19). Nesse sentido, essa "heterogeneidade multitemporal de cada nação", da qual nos fala Canclini, torna-se um conceito relevante para nós, pois estamos sempre, em função de nosso objeto de estudo, diante de um espaço "multi" no qual nos vemos compelidos a abordar as várias literaturas estrangeiras modernas cientes da importância do respeito às diferenças características de cada área de estudo específica.

Diante de tais argumentos, o objetivo deste texto não poderia ser, portanto, dar conta da complexidade dos conceitos teóricos acima arrolados, imbricados como estão em nosso contexto atual, quer seja no âmbito da pós-modernidade ou dos modernismos alternativos, pois essa seria uma tarefa inglória. Gostaria, então, de fazer um exercício crítico nas linhas propostas por Spivak, no excerto usado como epígrafe para este texto: como poderíamos pensar a pesquisa na área de literatura, e no nosso caso a literatura estrangeira moderna, como nossa "mestra" e nosso objeto de pesquisa, nossa meta em busca do "humano" - evocado já em nossa filiação à área de ciências humanas - por meio das várias formas de pensar o projeto coletivo neste novo século - um coletivo ou coletividade cuja característica inerente é o atravessamento de fronteiras? Para Spivak, a literatura comparada e os "estudos de área" podem e devem trabalhar juntos, uma vez que, para ela, ambas as disciplinas estão interconectadas e dependem uma da outra. $\mathrm{O}$ termos utilizado por Spivak, "estudos de área" ("area studies"), a meu ver, poderia equivaler, de um modo geral, a nossas literaturas estrangeiras modernas, embora em nosso caso, já ocorra certa "desestabilização do nacional", pois nossas literaturas estrangeiras se movem para além de estados-nação. A autora afirma que "complementar a literatura comparada com estudos de área (comparados) nos permite repensar as coletividades meramente nacionais em termos de origem" (Spivak, 2003, p. 53). 
Acredito que essa tem sido, e deva ser, uma das grandes metas da pesquisa em literaturas estrangeiras modernas na atualidade: interagir, de forma comparada, com outras áreas do saber, procurando pensar em coletividades que nos levem a questionar noções simplistas de origem. Podemos nos perguntar ainda que grande temas deveriam atrair nossa atenção neste começo de milênio? Qual o nosso papel como professores e orientadores encarregados de direcionar grande parte da pesquisa produzida na área no Brasil? Que espaço ocupamos neste contexto? Como fazer com que essa produção repercuta em/dialogue com outros espaços geográficos e políticos e que, por vezes, nos servem de objeto de pesquisa? Que tipos de fronteiras estamos inevitavelmente atravessando?

Nesse sentido, em vez de me ater aos "pós" da contemporaneidade, gostaria de propor uma teorização que nos leve além dos muitos "pós", isto é, em direção a outros questionamentos e a outras fronteiras, por meio de vários outros conceitos também atravessados pelos "pós" da contemporaneidade nesse novo século: conceitos tais como multiculturalismo, cosmopolitismo, globalização, planetariedade, entre outros. Questionamentos esses que nos direcionem para uma posição de defesa de um diálogo corajoso, por meio do quais várias formas de subjetividade e alteridades sejam confrontadas. Mais do oferecer respostas, me proponho a dialogar com e por meio de nosso objeto de estudo - a literatura - que é também nossa mestra, como nos lembra Spivak.

De modo mais específico, a primeira questão que se apresenta aqui é a de como dar conta da distância "espacial" inerente ao conceito de literaturas "estrangeiras" modernas - isto é, da distância entre o espaço intrínseco do nosso objeto de estudo literário ("estrangeiro") e nosso lócus de enunciação? Como nos lembra a crítica australiana-canadense Sneja Gunew, "os teóricos do pós-modernismo e do póscolonialismo sem dúvida precipitaram uma aceitação geral do fato de que a "posicionalidade", isto é, o local de onde se posiciona quando se fala, é central para a construção do conhecimento" (Gunew, 1995, p. 57). Nesse sentido, o que significa falar, do nosso lócus enunciativo, sobre literaturas "estrangeiras modernas" em tempos de pós e muito mais? Temos aqui dois significantes que merecem ser abordados mais detalhadamente: por um lado, falo dessa dimensão espacial evocada pelo termo "estrangeiro" e, por outro, de uma dimensão temporal, que está indelevelmente ligada ao termo "moderno" - donde se lê também "os vários "pós"da contemporaneidade e muito mais.

\section{Momento 2: Do estrangeiro}

Inicio, portanto, com uma argumentação sobre o termo "estrangeiro", que nos é comum e que compartilhamos. O conceito de estrangeiro, segundo nos lembra Kristeva, ao discutir o papel do estrangeiro nas sociedades contemporâneas, compartilha do unheimlich Freudiano, cujo sentido depreciativo está contido na própria etimologia da palavra "estranho/estrangeiro". Para Kristeva, o estrangeiro é ambiguamente a imagem do outro, da alteridade, mas é também aquele que vive dentro de nós, entre nós. É a face escondida da nossa própria identidade. Kristeva indaga ainda sobre a condição do estrangeiro na contemporaneidade - estrangeiro esse que sempre foi considerado um inimigo nas sociedades antigas. $\mathrm{O}$ estrangeiro nos leva, portanto, segundo a teorização de Kristeva, ao confronto com esse outro estranho - a quem rejeitamos por ser outro e ao mesmo tempo com quem nos identificamos, que nos fascina e que faz com que 
nossas fronteiras se esgarcem, que nossos conceitos seja revistos, pois somos todos, segundo ela, estrangeiros em nós mesmos (1991, p. 1-11).

Essa teorização nos leva a alguns questionamentos sobre a natureza do "estrangeiro" que evocamos quando falamos de literaturas estrangeiras modernas: somos, pois, nos dias de hoje capazes de viver, de teorizar, "com" os outros e também "como" outros? Como lidamos com o esforço de aceitar e formular novas modalidades, novas concepções de alteridades, de ver e teorizar aquilo que nos é estrangeiro?

Essa argumentação nos conduz a uma outra via teórica por meio de um exame crítico e pertinente sobre a noção de hospitalidade dada ao estrangeiro/estranho cuja presença marca de forma contundente a sociedade contemporânea e se torna, em muitos casos, ambiguamente nossos objetos de estudos e nossa disciplina mestra.

O conceito de hospitalidade, desenvolvido por Derrida, via Levinas, nos revela a possibilidade, por vezes negada, e por isso mesmo questionada, de uma acolhida incondicional do outro enquanto outro. Segundo Derrida, a lei da hospitalidade aparece como uma lei paradoxal, uma vez que a regra que determina a submissão do estrangeiro às leis do país anfitrião deveria também resguardar o respeito por e a aceitação de sua diferença por meio de uma "ética da hospitalidade". Porém, o que se observa é a inevitável associação da hospitalidade com uma hostilidade que deriva da dificuldade e mesmo da impossibilidade de aceitação incondicional do outro. O paradoxo encontra-se presente já na etimologia dos termos hospitalidade e hostilidade que remetem à possibilidade dúbia de "o estrangeiro (hostis) [ser] recebido como hóspede ou como inimigo" (2003, p. 41). Nesse sentido, tanto hóspede quanto hospedeiro se tornam peças cruciais no jogo das mobilidades sócio-culturais: tanto o hospedeiro quanto o hóspede são igualmente afetados e modificados pelos processos contemporâneos do devir em trânsito, processos esses que, nas palavras de Derrida, requerem que a vertente ética da tolerância e respeito ao outro sejam elaboradas e efetuadas.

Para o estrangeiro e hóspede, porém, a questão da língua prevalece como ponto de atrito e conflito, uma vez que esse ficará sempre condicionado à língua do outro, a ser julgado na língua do outro por sua própria condição de alteridade. No entanto, como argumenta Derrida, a relação do estrangeiro com a lei deve necessariamente passar pelo direito à cidadania, e como tal, por uma ética da hospitalidade incondicional ao outro, que está ligada aos direitos e deveres que a regem (2003, p. 23).

A teorização de Derrida suscita questionamentos relevantes quando pensamos as literaturas estrangeiras como nosso objeto de estudo nesse momento histórico de "pós e muito mais", nossos lugares como pesquisadores desse objeto outro que nos é estranho/estrangeiro, bem como nossos papéis como mediadores culturais e, por vezes, intérpretes da contemporaneidade. Somos, portanto, os hospedeiros desse outro (por acolher a visita do estrangeiro), aqueles que aceitam o outro e, paradoxalmente, compartilham com ele a sua língua e o inserem/divulgam, segundo as leis da hospitalidade, no seio da sociedade, sobretudo, acadêmica. Esse não é, porém, um contato inócuo ou imparcial. É, como todos os outros contatos culturais, uma zona na qual perspectivas múltiplas se encontram e, inevitavelmente, colidem entre si, como argumenta Mary Louise Pratt. É um processo que acaba por modificar, desestabilizar, de maneira produtiva, nossa percepção de certos conceitos teórico-críticos, bem como nos permite, de uma certa forma, intervir na teia de produção do conhecimento em outras paragens. Visto por esse lado, esse contato torna-se, portanto, uma via de duas mãos, um processo, nem sempre sereno, mas, sobretudo, questionador das possibilidades do fazer teórico e crítico, consciente do respeito pelo estrangeiro e por nós mesmos como estrangeiros nos olhos dos outros que nos servem de objeto de pesquisa, por meio da ética da hospitalidade por aquele ou aquilo que é estrangeiro. 
Sem esse entendimento, não creio que tenhamos como pensar a literatura estrangeira na contemporaneidade. Essa é uma questão que está no cerne de nosso papel como pesquisadores em Literaturas Estrangeiras Modernas: como tratar o outro, o estrangeiro em nosso fazer acadêmico e como ser tratada pelo outro como outro que também somos. Esse é um movimento que implica necessariamente um ir e vir contínuo, mas também o entendimento de que não se pode falar pelo outro ou em nome do outro.

\section{Momento 3: Do moderno}

Passamos agora, para um outro momento, em que nos parece relevante argumentar em termos temporais - de como estamos nos movendo - dentro dos "pós" - mas também "além" deles, caminhando para novos parâmetros discursivos advindos dos processos de transferências culturais, da globalização, da mundialização, do multiculturalismo, do cosmopolitismo contemporâneo, das várias formas de culturas em trânsito e da interação entre povos.

É claro que não se pode pensar uma categoria - espacial e temporal - desvinculada da outra, pois a condição atual requer que se "reconheçam os diferentes entrelaçamentos do temporal com o espacial e seu efeitos estéticos", como nos lembra Huyssen (2002, p. 24). Ou ainda, como explicita Appadurai ao teorizar o termo "localidade", trata-se de um processo de estar no mundo, uma "localidade", que implica muito mais uma concepção relacional e contextual do que uma relação meramente espacial (1996, p. 178).

Nesse sentido, como sujeitos continuamente em contato com o outro, com o estrangeiro, podemos indagar como a crítica literária contemporânea se posiciona frente a esses movimentos de "pós" e muito mais da atualidade. A globalização, compreendida como um conceito chave na contemporaneidade, tem produzido uma cultura em constante movimento e, consequentemente, o surgimento de um cenário de grande mudanças sociais, culturais e econômicas. Segundo Appadurai, a presente relação móvel entre a mediação eletrônica e a imigração em massa define a ligação entre a globalização e o moderno e impele o trabalho imaginativo e crítico, que é nosso objeto de estudo. Como um fenômeno complexo e multi-axial, a globalização informa não apenas o fluxo transnacional de capital, mas também o de pessoas em espaços sociais e zonas de contato nos quais diferentes perspectivas culturais se encontram e se chocam. Como a escritora canadense Eva Hoffman nos lembra, "o que acontece hoje é que os movimentos através de culturas se tornaram a norma em vez de exceção" (1999, p. 42). Torna-se importante, no entanto, indagar em quais circunstâncias ou condições esses movimentos ocorrem na sociedade contemporânea e qual o papel, neste processo, dos críticos literários - localizados ambiguamente entre o local/os locais e o global/os globais.

Não basta apenas, porém, como menciona a crítica canadense Diana Brydon, se esquivar dessas questões argumentando tão somente o efeito nefasto, e inevitável, do chamado "feitiço" da globalização. Para se enfocar os estudos da globalização - termo esse que tem sido usado aleatoriamente - faz-se necessário distinguir entre a definição de uma globalização nefasta e neoliberal e a globalização como um fenômeno complexo e multifacetado. Para Brydon, as muitas formas das globalizações (intencionalmente identificadas no plural) devem ser analisadas e teorizadas a partir de dois parâmetros distintos: a globalização vista por baixo, por aqueles que sofrem seus efeitos perversos, e a globalização vista por cima, pelas instituições que fazem parte dos mecanismos globais (2001, p. 68-71). 
Andreas Huyssen, por outro lado, argumenta que, embora a globalização vá "mudar o campo dos estudos culturais e literários", ela, com certeza atualmente é a formulação teórica que "fornece o horizonte para nosso trabalho como comparatistas" e críticos literários e culturais (2002, p. 15-16). Segundo ele, "Em uma época em que se espera dos estudos literários que cubram cada vez mais território, geográfica e historicamente, sobrecarregando, assim, os circuitos de qualquer crítico, o perigo é a disciplina perder sua coerência como campo de pesquisa, atolar-se em estudos de casos locais ou tornar-se superficial, negligenciando a necessidade de manter um projeto metodológico e teórico" (2002, p.18). Nesse caso, a seu ver, a globalização requer do crítico cultural uma visão que não se restrinja a casos meramente locais e um modelo para o estudo comparado que "atravesse fronteiras, línguas e culturas, o tipo de estudo comparado que pode ajudar a nutrir um novo sentido de conexão" (2002, p. 19). Argumenta ainda que "a própria noção de comparação deve ser problematizada", pois "não estamos mais comparando unidades culturais separadas", mas sim investindo em conceitos novos que requerem uma reflexão acerca das "questões de tradução e tradutibilidade, migração, transmissão e apropriação" (2002, p. 23). Em outras palavras, os estudos de áreas isolados ou de "unidades culturais separadas" não dão conta mais da complexidade das interações humanas, sociais e culturais da contemporaneidade. Essas são temáticas centrais para a discussão do papel dos críticos e pesquisadores em literaturas estrangeiras modernas na atualidade.

$\mathrm{Na}$ verdade, os críticos atuais têm abordado, cada vez mais, esse novo fenômeno, principalmente sob o enfoque das relações de gênero, classe e raça, categorias imprescindíveis para se pensar a literatura contemporânea hoje. Resta indagar em quais condições e circunstâncias esses textos críticos surgem e quais desafios trazem para uma análise da produção literária atual face aos movimentos globais da contemporaneidade. Esse é, sem dúvida, um dos grandes desafios que aguardam os pesquisadores das áreas de literaturas estrangeiras modernas na atualidade, principalmente no sentido de procurar "manter um projeto metodológico e teórico", como afirma Huyssen (2002, p. 23).

Nesse contexto, podemos salientar o papel crucial de críticos, mas também de artistas e escritores ao projetarem, através da escrita, do fazer crítico e literário, uma experiência do devir em trânsito, como uma possível forma de resistir a iniciativas homogeneizantes, deslocar posicionamentos, abrir novas frentes e criar modelos alternativos que fomentem um diálogo que, em um contexto transnacional ou pósnacional (segundo Appadurai), possa levar a formas instigantes de percepção e questionamentos dos discursos da contemporaneidade.

Nesse sentido, um conceito mais amplo de mobilidade no mundo global da contemporaneidade pode ser compreendido como uma forma de cosmopolitismo, ou como argumenta Bruce Robbins, como uma cosmopolítica (cosmopolitics). Segundo Robbins, "o cosmopolitismo oferece algo mais do que uma galeria de identidades virtuosas, elegíveis. Aponta, em vez disso, para um domínio de políticas contestatórias [...] [a cosmopolítica] como uma área ao mesmo tempo dentro e além da nação [...] habitada por uma variedade de cosmopolitismos" (1998, p. 12). É nesse contexto relativo a movimentos globais, bem como ao cosmopolitismo e à cosmopolítica, que podemos analisar nosso papel como pesquisadores e teóricos da contemporaneidade, ou seja, de que forma esses novos conceitos da contemporaneidade são apresentados e como contribuem para fomentar um campo de políticas contestatórias em nossa área?

Se, por um lado, esse mundo contemporâneo se caracteriza pela confluência de locais geopolíticos, pela eliminação de fronteiras e compartilhamento de espaços sociais; por outro, mostra-se cada vez mais sectário e excludente nas práticas cotidianas. 
Essa ambigüidade está no cerne da teorização sobre os movimentos culturais da contemporaneidade. Como nos lembra Silviano Santiago em "O cosmopolitismo do pobre", "Uma nova e segunda forma de multiculturalismo pretende (1) dar conta do influxo de migrantes pobres, na maioria ex-camponeses, nas megalópoles pósmodernas, constituindo seus legítimos e clandestinos moradores, e (2) resgata, de permeio, grupos étnicos e sociais, economicamente desfavorecidos no processo assinalado de multiculturalismo a serviço do estado-nação" (Silviano, 2004, p. 59). Nesse sentido, a modernidade, em seu sentido amplo, não acarretaria um trabalho imaginativo apenas emancipatório, mas principalmente uma espaço de contestação nos quais indivíduos e grupos podem contestar o global em suas práticas modernas (Appadurai, 1996, p.4).

Volto então às palavras de Spivak sobre a importante construção de coletividades contemporâneas no mundo intrinsecamente cosmopolita - ponto crucial para se refletir sobre a literatura comparada e os estudos de área. Segundo a autora, as coletividades atravessam fronteiras sob os auspícios da literatura comparada, suplementada pelos estudos de área, e podem ser pensadas em termos de uma "planetariedade" compartilhada, em vez de continental, global ou mundial. Spivak delineia um novo sentido para o conceito de globalização ao contrastá-lo ao termo cunhado por ela, planetaridade, enfatizando a alteridade e humanidade do planeta em oposição à construção e artificialidade do globo (2003, p. 72). Esse novo termo é relevante para a análise em tela, pois permite uma visão renovada da atual globalização, cujo vocábulo se encontra já desgastado pelo uso freqüente e aleatório. Sua proposta é a de que a noção de "planeta" como metáfora para uma reflexão sobre o contexto atual se sobreponha a do "globo". Para ela, o globo é artificial uma vez que ninguém vive lá; já o planeta, em sua concepção, pertence a um outro sistema no qual, nós os humanos habitamos; logo, está ligado à espécie da alteridade - no sentido de que ser humano é estar voltado em direção ao outro, como nos lembra Hannah Arendt. Essa concepção de planetariedade para Spivak está inerentemente ligada ao papel transformador tanto da literatura comparada quando dos estudos de área - o que, para ela, resguardaria o que muitos têm visto como a morte de uma disciplina (Spivak, 2003, p. 72-73). Para ela, literatura comparada e estudos de área oferecem uma "solidariedade" das bordas que são facilmente atravessadas, uma vez que essas disciplinas necessariamente atravessam fronteiras (Spivak, 2003, p. 15-16) - como as nossas o fazem. E nós somos, muitas vezes, aqueles que viabilizam esse atravessamento. Não se trata, a meu ver, de substituir um termo por outro - globalização por planetariedade -, mas sim de criar novas formas de pensar o contemporâneo que não esteja já fossilizado pela inserção acadêmica de um conceito ou, neste caso, por sua inserção também mercadológica.

\section{Momento 4: Da ação}

Como disciplinas inerentemente fronteiriças, como argumenta Spivak, tanto a literatura comparada quanto as literaturas estrangeiras modernas têm que lidar hoje com um novo conceito de estar no mundo e com sujeitos em um movimento errante. Esses sujeitos são hoje detentores de uma cidadania transitória que reflete um novo posicionamento em relação a um contexto espacial específico, que é movente, transitório e múltiplo. Rey Chow argumenta, apropriadamente, que a experiência da mobilidade cultural na pós-modernidade e na globalização não é apenas uma condição histórica, mas, é, sobretudo, uma realidade intelectual, isto é, a realidade de ser um intelectual da contemporaneidade (Chow, 1993, p. 15). 
Nesse cenário, é relevante destacar, sobretudo, o papel do intelectual contemporâneo, por vezes um autor cosmopolita, que observa, analisa e questiona os vários processos críticos que perpassam a pós-modernidade. Diria, inclusive, que esta é, principalmente, a nossa situação como críticos voltados ao estudo das literaturas estrangeiras modernas, pois estamos inevitavelmente inseridos, pela própria condição de produção material de nossa pesquisa, aos efeitos dos movimentos transfronteiriços, quer seja por meio da literatura de língua inglesa, francesa, alemã, espanhola, entre outras.

Essa questão nos remete ao processo do fazer estético e literário que também é perpassado pela ética do intelectual, daquele que, nas palavras de Hannah Arendt em $A$ condição humana, é capaz de fazer das palavras e dos discursos veículos para a ação, uma das atividades humanas fundamentais, cuja condição básica é a pluralidade (2005, p. 189). De forma contundente, é preciso questionar e problematizar a experiência literária nesse nosso momento histórico de vários "pós" e muito mais, de múltiplos espaços e lugares ambivalentes do trânsito cultural no qual habitam simultaneamente os vários estrangeiros e sujeitos em trânsito. São espaços que compartilham com o estrangeiro um sentimento de repulsa e atração; ao mesmo tempo que são espaços de hospitalidade, são também locais de hostilidade para o estrangeiro/estranho com o qual devemos interagir em um processo contínuo e ambíguo de estar com o outro. Esse, acredito, é o desafio que se coloca para nós que fazemos pesquisa na área de literaturas estrangeiras modernas: dar conta tanto do estrangeiro quanto do moderno por meio da condição que hoje ocupamos - tão humana - como intelectuais contemporâneos cujas palavras/discursos têm, acredito, o poder da ação - às vezes maior, às vezes menor.

Nesse contexto, nossa tarefa de trabalhar com a pesquisa em tempos de pós, bem como nosso objeto de trabalho nunca estiveram em tanta evidência e, possivelmente, nunca tiveram um papel tão relevante quanto tem hoje diante do contexto, acima delineado, de novas perspectivas de interação sócio-culturais e novas percepções dos movimentais espaciais e temporais da contemporaneidade. É um momento em que, como nos lembra Huyssen, uma configuração lateral ou horizontal - e não mais vertical - dá lugar a uma zona fronteiriça de trocas, de contatos trans- e pós- nacionais, multiculturais e de tipos variados de intervenções híbridas (2002, p. 29).

Nosso papel e nossa ação, portanto, como lembram vários críticos, devem ser o de pensar o literário em um contexto espaço-temporal de ramificações múltiplas e várias convergências possíveis, sem contudo, ceder à análise das abordagens teóricas atuais que levam "à tradução fácil de vocabulários críticos de um contexto intelectual e geopolítico para outro" (Huyssen, 2002, p. 32), garantindo uma certa especificidade da ordem do local que pode nos ajudar a entender e questionar nossos momentos históricos mais significativos.

Torna-se relevante neste contexto pensar também em termos das possibilidades intervencionistas de nossas habilidades de leitura crítica - daquela de que nos fala Spivak - evocadas como forma de contrapor o que muitos crêem ser um momento de estagnação da área (Huyssen) ou de uma possível morte de uma disciplina (Spivak) em busca de uma visão mais inclusiva e transformadora da área. Como nos lembra Huyssen, aqui nos parece importante "usar como fonte os debates sobre sociedade civil, comunidades imaginárias, gênero, subalternidade e o debate emergente sobre imaginários urbanos transnacionais", além de "reintroduzir tópicos de qualidade estética em nossa análise de toda prática e todo produto cultural" (2002, p. 30-31). Para tal, como argumenta Spivak, o próprio estudo da literatura por meio de uma restauração do papel do ensino da literatura como forma de trabalhar a imaginação criativa poderá nos fornecer os subsídios para uma despolitização da política da hostilidade (ao estrangeiro) em direção a uma política da amizade (2003, p. 13). Diria que esse é um exercício da 
hospitalidade, de que tratamos no início deste texto, que inevitavelmente passa por um aprendizado da língua do outro - não no sentido lingüístico costumeiro -, mas na forma de compreender as nuances de contextos sócio-culturais por meio da linguagem. Spivak nos fala da necessidade de nos engajar com o idioma do(s) outro(s) global como uma forma de "deslocar/desestabilizar a disciplina" (2003, p. 10). A autora parece especialmente preocupada com o que ela percebe como sendo a inabilidade institucional de lidar com a literatura e os cruzamentos com as categorias de raça, gênero e classe nas teorizações literárias e as várias formas de "interseccionalidades" entre esses termos. Essa preocupação remete a seu argumento principal de como a literatura pode nos ensinar, isto é, pode ser nossa mestra e, ao mesmo tempo, nosso objeto de estudo.

Termino, portanto, refletindo sobre nosso objeto de estudo e trabalhando a linguagem que nos permite desestabilizar conceitos preestabelecidos. Cito uma bela passagem do romance da escritora estadunidense, de origem indiana, Jhumpa Lahiri, no romance The Namesake (O Homônimo), no qual uma das personagens descreve a experiência contemporânea do estrangeiro e do trânsito através do corpo, porém, um corpo outro que se qualifica como feminino e grávido:

Ser um estrangeiro, Ashima está começando a entender, é uma forma de gravidez que dura a vida toda - uma espera perpétua, um fardo constante, um sentimento contínuo de indisposição. É uma responsabilidade constante, um parêntesis no que fora um dia uma vida comum, apenas para descobrir que aquela vida prévia desapareceu, foi substituída por algo mais complicado e incontestável. Como uma gravidez, ser um estrangeiro, Ashima acredita, é algo que evoca a mesma curiosidade dos estranhos, a mesma combinação de pena e respeito (2003, p. 49-50).

Ao relacionar a experiência do estrangeiro e do outro com a experiência da gravidez, ou seja, ao procurar por uma definição de seu estado nos olhos do outro, a personagem expressa de forma contundente a relação intrínseca, entre essa nova configuração contemporânea do estrangeiro e o predicamento da maternidade em termos de gênero e do feminino. Esse se torna o elemento diferenciar dessa forma de mobilidade contemporânea, na visão de críticos contemporâneos como Spivak, Clifford, Chow, com a qual corroboro. $\mathrm{O}$ estrangeiro é o mesmo, mas é também o outro, como nos lembra Kristeva.

Nesse sentido, se, como professores e pesquisadores de literaturas estrangeiras modernas, pudermos instigar nossos alunos a ler, a pensar novas formas de ler o literário neste espaço dúbio do estar com o outro, por meio de nossas pesquisas, através de um diálogo produtivo com outras literaturas estrangeiras modernas e a literatura comparada, então poderemos, de fato, pensar em nossa ação como algo humano que se move em direção a várias e outras coletividades nesses tempos de pós e muito mais.

\section{REFERÊNCIAS BIBLIOGRÁFICAS:}

APPADURAI, Arjun. Modernity at Large: Cultural Dimensions of Globalization. Minneapolits: University of Minnesota Press, 1996.

ARENDT, Hannah. A condição humana. Rio de Janeiro: Forense Universitária, 2005.

BRYDON, Diana. Global Designs, Postcolonial Critiques: Rethinking Canada in Dialogue with Diaspora. Ilha do Desterro, Florianópolis, v. 40, p. 61-84, 2001.

CHOW, Rey. Writing Diaspora: Tactics of Intervention in Contemporary Cultural Studies. Bloomington and Indianópolis: Indiana University Press, 1993.

DERRIDA, Jacques; DUFOURMANTELLE, Anne. Da hospitalidade. Anne Dufourmantelle convida Derrida a falar da hospitalidade. Tradução de Antonio Romane. São Paulo: Escuta, 2003. 
GARCÍA CANCLINI, Néstor. Culturas híbridas: estratégias para entrar e sair da modernidade. São Paulo: Editora da UNESP, 2000.

GUNEW, Sneja. Framing Marginality: Multicultural Literary Studies. Melbourne: Melbourne University, 1995.

HOFFMAN, Eva. The New Nomads. In: ACIMAN, Charles (Ed.). Letters of Transit: Reflections on Exile, Identity, Language, and Loss. New York: The New Press, 1999. p. 3563.

HUYSSEN, Andreas. Literatura e cultura no contexto global. In: MARQUES, Reinaldo, VILELA, Lúcia Helena (Orgs.). Valores: arte, mercado, política. Belo Horizonte: Editora UFMG, 2002. p. 15-33.

KRISTEVA, Julia. Strangers to Ourserlves. Tradução de Leon S. Roudiez. New York: Columbia University Press, 1991.

MIGNOLO, Walter. Local Histories/Global Designs: Coloniality, Subaltern Knowledges, and Border Thinking. Princeton: Princeton UP, 2000.

PRATT, Mary Louise. Imperial Eyes: Travel Writing and Transculturation. London and New York: Routledge, 1992.

ROBBINS, Bruce. Introduction Part I: Actually Existing Cosmopolitanism. In: CHEAH, Pheng; ROBBINS, Bruce (Eds.). Cosmopolitics: Thinking and Feeling beyond the Nation. Minneapolis: Minnesota UP, 1998. p. 1-19.

SANTIAGO, Silviano. O Cosmopolitismo do pobre. Belo Horizonte: Editora UFMG, 2004.

SARLO, Beatriz. Tempo passado: cultura da memória e guinada subjetiva. São Paulo, Belo Horizonte: Cia. das Letras/Editora UFMG, 2007.

€SPIVAK, Gayatri. Death of a Discipline. New York: Columbia University Press, 2003. 